\title{
Mouse Acidic Chitinase Effectively Degrades Random-Type Chitosan to Chitooligosaccharides of Variable Lengths under Stomach and Lung Tissue $\mathrm{pH}$ Conditions
}

\author{
Satoshi Wakita ${ }^{1}$, Yasusato Sugahara ${ }^{1}$, Masayuki Nakamura ${ }^{1}$, Syunsuke Kobayashi ${ }^{1}$, Kazuhisa Matsuda ${ }^{1}$,

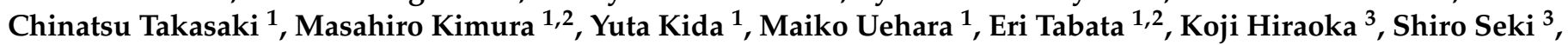 \\ Vaclav Matoska ${ }^{4}$, Peter O. Bauer ${ }^{4,5}$ and Fumitaka Oyama ${ }^{1, *(D)}$ \\ Citation: Wakita, S.; Sugahara, Y.; \\ 1 Department of Chemistry and Life Science, Kogakuin University, Tokyo 192-0015, Japan; \\ wsat.chorus.618@gmail.com (S.W.); bt79310@ns.kogakuin.ac.jp (Y.S.); \\ nakamura.shibatagousei@gmail.com (M.N.); shuukatsu1215@gmail.com (S.K.); \\ heimonana@icloud.com (K.M.); bm19024@g.kogakuin.jp (C.T.); bd17002@g.kogakuin.jp (M.K.); \\ yuta.maldini@blue.email.ne.jp (Y.K.); bd19001@ns.kogakuin.ac.jp (M.U.); bq21002@ns.kogakuin.ac.jp (E.T.) \\ 2 Japan Society for the Promotion of Science (PD), Tokyo 102-0083, Japan \\ 3 Department of Environmental Chemistry, Kogakuin University, Tokyo 192-0015, Japan; \\ bm18040@g.kogakuin.jp (K.H.); shiro-seki@cc.kogakuin.ac.jp (S.S.) \\ 4 Laboratory of Molecular Diagnostics, Department of Clinical Biochemistry, Hematology and Immunology, \\ Homolka Hospital, Roentgenova 37/2, 15000 Prague, Czech Republic; vaclav.matoska@homolka.cz (V.M.); \\ peter.bauer@bioinova.cz (P.O.B.) \\ 5 Bioinova JSC, Videnska 1083, 14220 Prague, Czech Republic \\ * Correspondence: f-oyama@cc.kogakuin.ac.jp
} Nakamura, M.; Kobayashi, S.; Matsuda, K.; Takasaki, C.; Kimura, M.; Kida, Y.; Uehara, M.; Tabata, E.; et al. Mouse Acidic Chitinase Effectively Degrades Random-Type Chitosan to Chitooligosaccharides of Variable Lengths under Stomach and Lung Tissue $\mathrm{pH}$ Conditions. Molecules 2021, 26, 6706. https://doi.org/ $10.3390 /$ molecules 26216706

Academic Editor: Gordon Morris

Received: 6 October 2021

Accepted: 3 November 2021

Published: 5 November 2021

Publisher's Note: MDPI stays neutral with regard to jurisdictional claims in published maps and institutional affiliations.

Copyright: (c) 2021 by the authors Licensee MDPI, Basel, Switzerland. This article is an open access article distributed under the terms and conditions of the Creative Commons Attribution (CC BY) license (https:// creativecommons.org/licenses/by/ $4.0 /)$.

\begin{abstract}
Chitooligosaccharides exhibit several biomedical activities, such as inflammation and tumorigenesis reduction in mammals. The mechanism of the chitooligosaccharides' formation in vivo has been, however, poorly understood. Here we report that mouse acidic chitinase (Chia), which is widely expressed in mouse tissues, can produce chitooligosaccharides from deacetylated chitin (chitosan) at $\mathrm{pH}$ levels corresponding to stomach and lung tissues. Chia degraded chitin to produce $\mathrm{N}$-acetyl-D-glucosamine (GlcNAc) dimers. The block-type chitosan (heterogenous deacetylation) is soluble at $\mathrm{pH} 2.0$ (optimal condition for mouse Chia) and was degraded into chitooligosaccharides with various sizes ranging from di- to nonamers. The random-type chitosan (homogenous deacetylation) is soluble in water that enables us to examine its degradation at $\mathrm{pH}$ 2.0, 5.0, and 7.0. Incubation of these substrates with Chia resulted in the more efficient production of chitooligosaccharides with more variable sizes was from random-type chitosan than from the block-type form of the molecule. The data presented here indicate that Chia digests chitosan acquired by homogenous deacetylation of chitin in vitro and in vivo. The degradation products may then influence different physiological or pathological processes. Our results also suggest that bioactive chitooligosaccharides can be obtained conveniently using homogenously deacetylated chitosan and Chia for various biomedical applications.
\end{abstract}

Keywords: acidic chitinase; block-type chitosan; chitin; chitooligosaccharides; FACE method; random-type chitosan

\section{Introduction}

Chitin is a polysaccharide abundantly occurring in nature and consisting of $\beta-1,4-$ linked N-acetyl-D-glucosamine (GlcNAc). It functions as the major structural component of the exoskeleton of crustaceans and insects, microfilarial shells of nematodes, and cell walls of fungi [1]. Chitin exists in three major forms- $\alpha$ [2-4], $\beta$ [4], and $\gamma[5,6]-$ differing in the orientation and packing of the polymeric chains.

Chitosans form a large family of heteropolymers of D-glucosamine (GlcN) and GlcNAc residues at various ratios and patterns. They are partially deacetylated derivatives of chitin. 
Chitosan can be prepared from chitin by two fundamentally different methodsheterogeneous and homogeneous deacetylation [7]. Heterogeneously deacetylated chitosan (hereafter called "block-type chitosan") with a deacetylation degree (DD) of up to 80\% maintain certain degree of crystallinity. Homogeneous deacetylation results in randomtype polymers (hereafter called "random-type chitosan") [8]. The random-type chitosan with a DD of $\sim 50 \%$ is soluble in water. The crystallinity of the molecules decreases rapidly with the DD of $>40 \%$ and these molecules are defined as amorphous [8].

Although humans and mice do not synthesize endogenous chitin, they produce two active chitinases, chitotriosidase, and acidic chitinase (hereafter referred to as "Chia"; also reported as acidic mammalian chitinase, "AMCase") [9-13]. Chia has been an attractive subject in biomedical research because its levels are altered in various diseases such as asthma, allergic inflammation, gastric cancer, ocular allergy, and dry eye syndrome [14-20]. In addition, polymorphisms in the Chia gene are associated with bronchial asthma in humans [21-23]. Recently, it has also been shown that chitinase activity in mouse airways depends on Chia $[24,25]$.

Mouse Chia mRNA is predominantly expressed in the stomach [13,26,27], followed by the submaxillary gland and lung [26]. Recombinant Chia has peak activity at a $\mathrm{pH}$ of around 2.0 that gradually decreases at more neutral conditions ( $\mathrm{pH} 3.0-7.0)$, primarily producing (GlcNAc) 2 [28-31]. In addition, mouse Chia exhibits transglycosylation activity under neutral conditions [32]. Chia is resistant to digestion by proteases in mice, chickens, pigs, and common marmosets under gastrointestinal-like conditions [33-37].

Several recent reports have indicated that chitooligosaccharides derived from chitin and chitosan are biologically active and have anti-tumorigenic and anti-inflammatory effects [38-41]. Chitooligosaccharides can be produced by chemical or enzymatic methods [42,43]. Enzymatic preparation by nonspecific enzymes-such as cellulases, lipases, chitosanases, and proteases, including commercially available porcine pepsin preparationshave been used to produce chitooligosaccharides with various biomedical activities [44-46].

We have recently reported that Chia residues in porcine pepsin preparations exhibit chitinolytic activity under the stomach condition [47]. It remains elusive whether Chia can efficiently digest chitosan under physiological conditions of peripheral tissues, such as the lungs.

In this study, we show that mouse Chia produces chitooligosaccharides under such conditions and that the random-type chitosan is more suitable for efficient and production of oligomers of variable sizes when compared with the block-type form of the molecule $[7,8]$.

\section{Results}

\subsection{Degradation of $\alpha$-and $\beta$-Colloidal Chitin Substrates}

We incubated $\alpha$ - or $\beta$-colloidal chitin ( $\alpha$ - or $\beta$-chitin) at $\mathrm{pH} 2.0$ and $37^{\circ} \mathrm{C}$ for 1,24 , or $72 \mathrm{~h}$ and analyzed the degradation products by the fluorophore-assisted carbohydrate electrophoresis (FACE) method.

We mainly detected (GlcNAc) $)_{2}$ from $\alpha$-chitin, whereas $\beta$-chitin was degraded into chitooligosaccharides of different sizes-including dimers, trimers and, with lower efficiency, also longer molecules (Figure 1). As we have reported previously, element analysis showed a higher degree of deacetylation (DD) in $\beta$-chitin when compared to that of $\alpha$-chitin [47]. Thus, the relationship between higher chitin DD and the production of longer chitooligosaccharides observed with porcine Chia [47] can also be seen in case of mouse Chia. 


\section{a-Colloidal chitin}

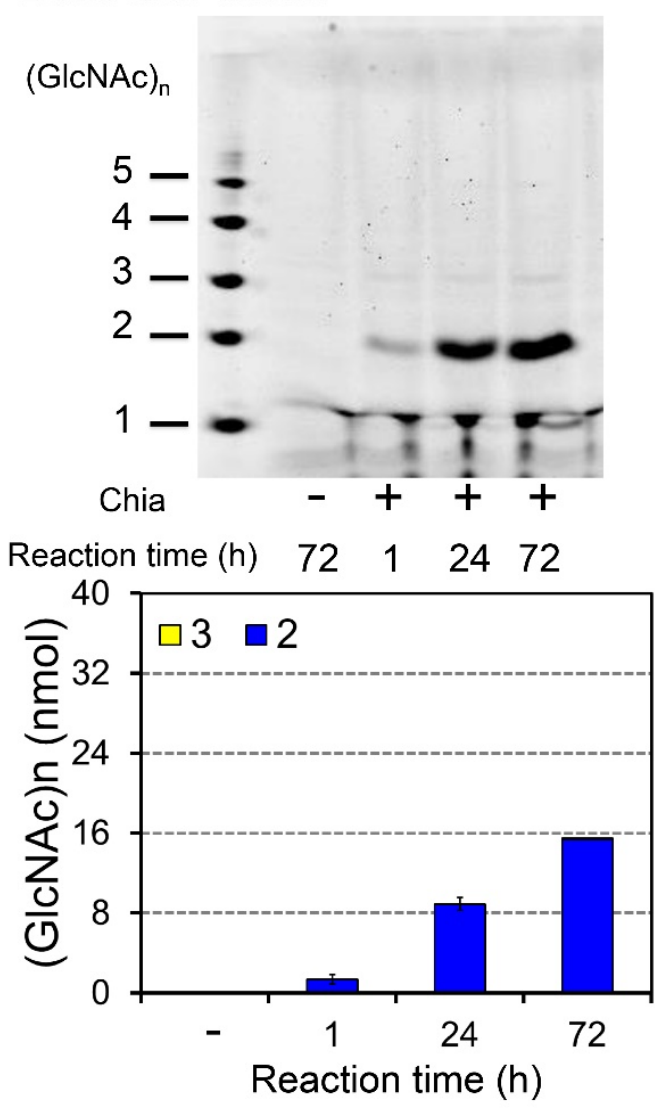

\section{$\beta$-Colloidal chitin}
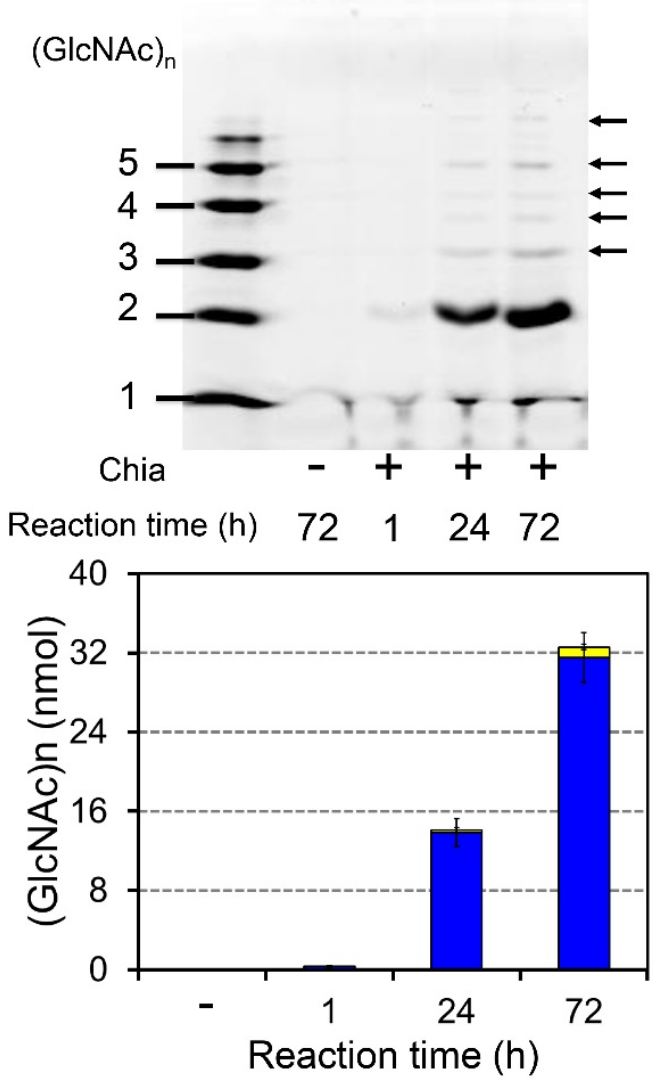

Figure 1. Degradation of $\alpha$ - and $\beta$-chitin substrates by Chia. $\alpha$-colloidal or $\beta$-colloidal chitin was incubated with $\mathrm{Chia}$ at $\mathrm{pH}$ 2.0 for 1, 24, or $72 \mathrm{~h}$. The resulting products were analyzed by the FACE method as described in the Materials and Methods. Chitin oligomers are shown in the left margin as standards. Recombinant Chia degraded $\alpha$-chitin (left) and generated primarily dimers, whereas GlcNAc oligomers of variable sizes were produced from $\beta$-chitin (right). The data quatification is shown in lower panels.

\subsection{Characterization of Block-Type and Random-Type Chitosan Substrates by X-ray Diffraction}

We analyzed the relationship between the degradation pattern, deacetylation mode and DD. We characterized the block- and random-type chitosan as well as $\alpha$ - and $\beta$-chitin substrates by X-ray diffraction, as described in Materials and Methods. $\alpha$ - and $\beta$-chitin exhibited characteristic peaks of $2 \theta=9.5^{\circ}$ and $19.5^{\circ}$, and $2 \theta=8.36^{\circ}$ and $19.72^{\circ}$, respectively (Figure 2), consistently with previous reports $[6,8,48]$.

Block-type chitosans with 69\%, 73\%, 84\%, and 95\% DD (chitosan 7B, 8B, 9B, 10B, Funakoshi Co., Ltd., Tokyo Japan) showed characteristic pattern $\left(2 \theta=20.06\right.$ to $\left.20.30^{\circ}\right)$ responding to DD and peaking at $84 \%$ DD (Figure 2) that represents the amorphous form of the molecule. Random-type chitosan shows the pattern of an amorphous molecule [8]. 


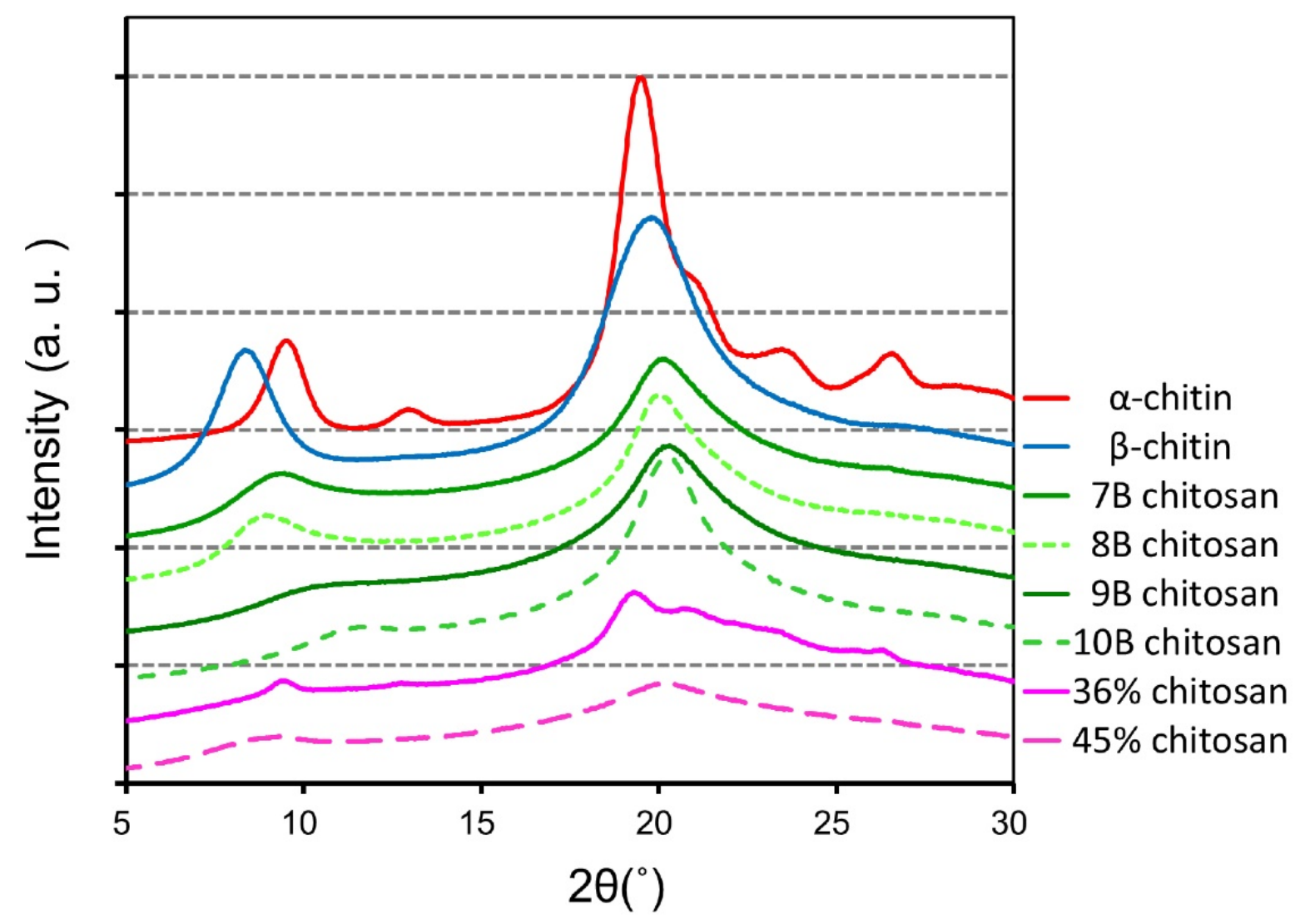

Figure 2. Observed X-ray diffraction patterns of block-type and random-type chitosan as well as $\alpha$-and $\beta$-chitin substrates. The phase compositions of chitin and chitosan substrates were recorded at room temperature by X-ray diffraction.

\subsection{Degradation of Block-Type Chitosan}

Next, we examined the degradation of block-type chitosans (Table 1). This type of chitosan is soluble at $\mathrm{pH} 2.0$, which is the optimal condition for Chia $[13,28]$. The substrates were dissolved in Mcllvaine buffer ( $\mathrm{pH} 2.0$ ), incubated with Chia at $37^{\circ} \mathrm{C}$ for 1,24 , or $72 \mathrm{~h}$ and analyzed by the FACE method.

Table 1. Property of chitin and chitosan.

\begin{tabular}{ccccc}
\hline & DD (\%) & Colloidal & Acidic Solution & Water \\
\hline$\alpha$-chitin & 2.1 & + & - & - \\
$\beta$-chitin & 10.2 & + & - & - \\
\hline \multirow{3}{*}{ Block-type chitosan } & 69 & - & + & - \\
& 73 & - & + & - \\
& 84 & - & + & - \\
\hline \multirow{2}{*}{ Random-type chitosan } & 95 & - & + & + \\
& 35 & - & + & + \\
\hline
\end{tabular}

Chia digested the substrates with up to $84 \%$ DD primarily to (GlcNAc) ${ }_{2},(\mathrm{GlcNAc})_{3}$, $\left(\right.$ GlcNAc) ${ }_{6}$, and (GlcNAc) 9 (Figure 3). More prolonged incubation ( $24 \mathrm{~h}$ and $72 \mathrm{~h} \mathrm{vs.} 1 \mathrm{~h}$ ) markedly increased the yield of the degradation. With increasing DD, the reaction efficiency decreased, and 95\% DD chitosan remained undigested (Figure 3). Thus, mouse Chia acts in this regard in a similar manner as the porcine enzyme [47]. These results indicate that mouse Chia has primarily chitinase but not chitosanase activity. 


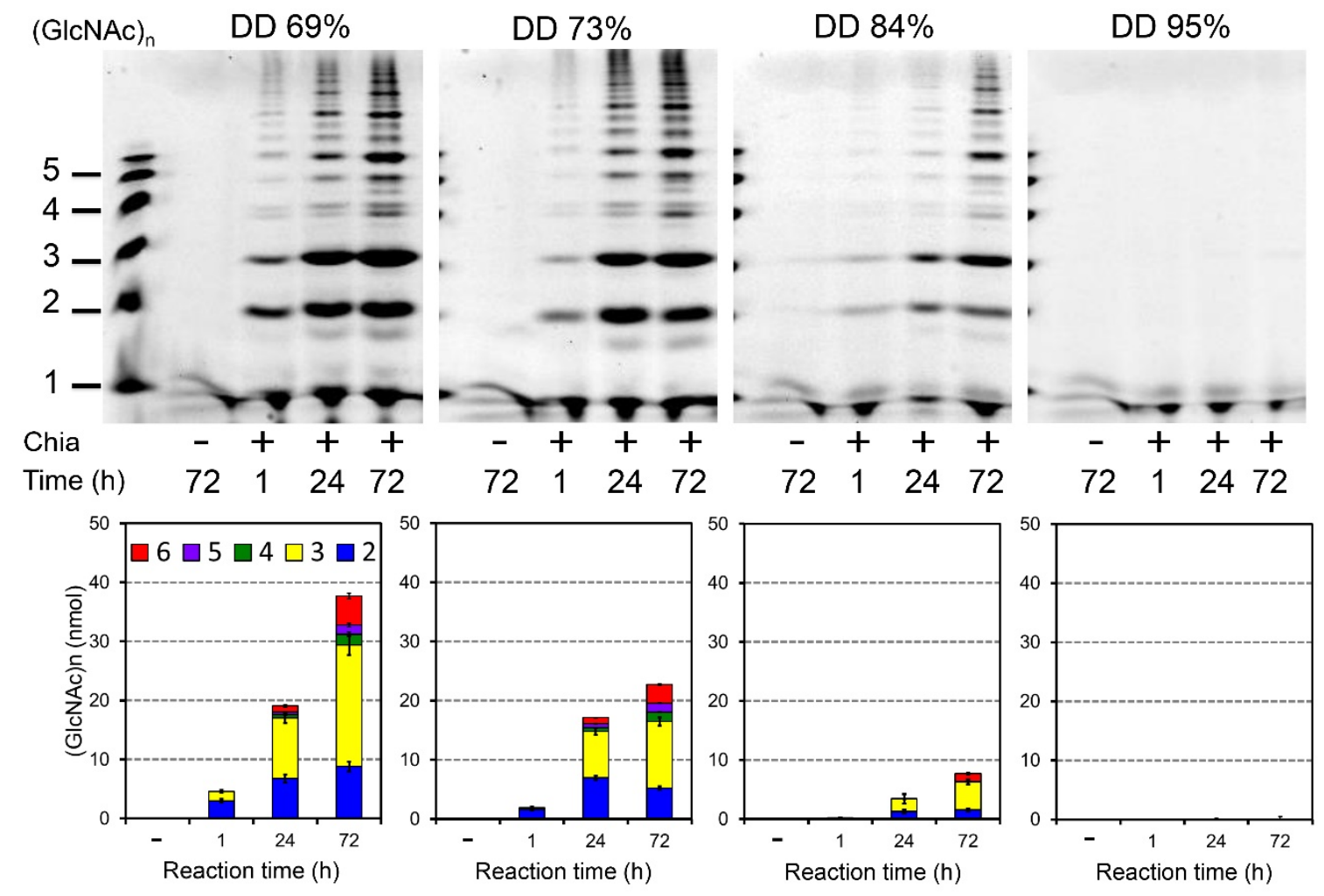

Figure 3. Degradation of block-type chitosan by Chia. Chitosan substrates (DD 69\%, 73\%, 84\%, and 95\%) were dissolved in McIlvaine buffer ( $\mathrm{pH}$ 2.0) and incubated with mouse Chia at $37^{\circ} \mathrm{C}$ for 1,24 , or $72 \mathrm{~h}$ and analyzed by the FACE method as described in the Materials and Methods. The degradation products obtained from block-type chitosan primarily consisted of (GlcNAc) 2 to (GlcNAc) 9 as well as longer chitooligosaccharides. Chia can degrade block-type chitosan with up to DD $84 \%$, whereas it could not degrade DD 95\%. Chitin oligomers are shown in the left margin as standards. Quantification of the data is shown in lower panels.

\subsection{Degradation of Random-Type Chitosan}

We next aimed to analyze how Chia degrades the random-type chitosan at different $\mathrm{pH}$ conditions. In contrast to the block-type chitosan, this type of chitosan is directly soluble in water (Table 1). Thus, the solubilized substrates with $36 \%$ and $45 \%$ DD were incubated with Chia in the Mcllvaine buffer at $\mathrm{pH} 2.0,5.0$, or 7.0 for $1 \mathrm{~h}$ and analyzed by the FACE method. Figure 4A shows chitooligosaccharides with various sizes generated from the $36 \%$ DD chitosan under-tested $\mathrm{pH}$ conditions. Prolonged incubation ( 24 and $72 \mathrm{~h}$ ) markedly increased the yield but did not change the ratio of the chitooligosaccharides.

Processing of the $45 \%$ DD molecule provided similar results (Figure 4B). However, we observed $\mathrm{pH}$ dependency with higher and lower DD leading to increased degradation products at $\mathrm{pH} 2.0$ and 7.0, respectively, at $24 \mathrm{~h}$. Thus, the DD of the random-type chitosan can influence the degradation of the substrates by Chia under different $\mathrm{pH}$ conditions. 


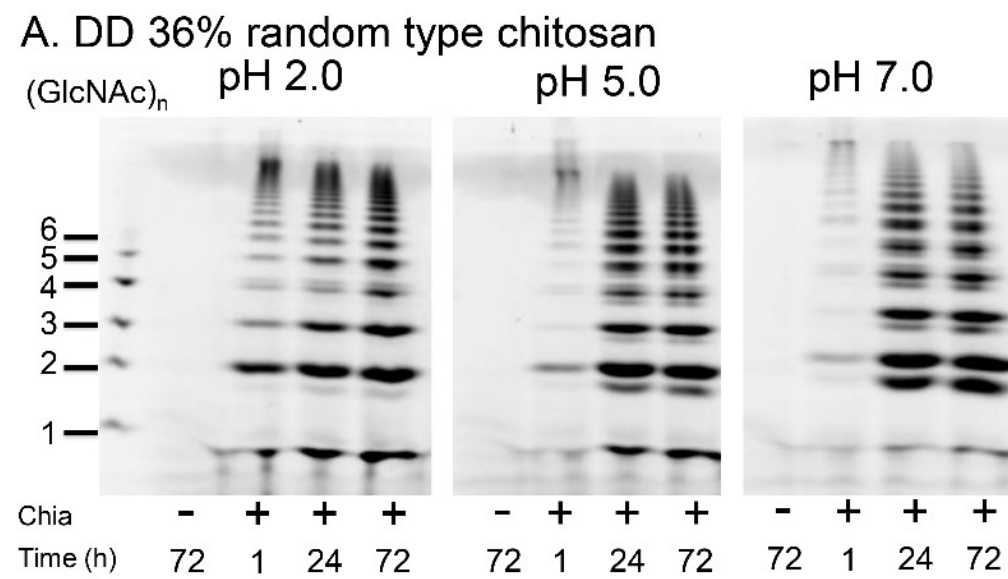

\section{B. DD $45 \%$ random type chitosan}
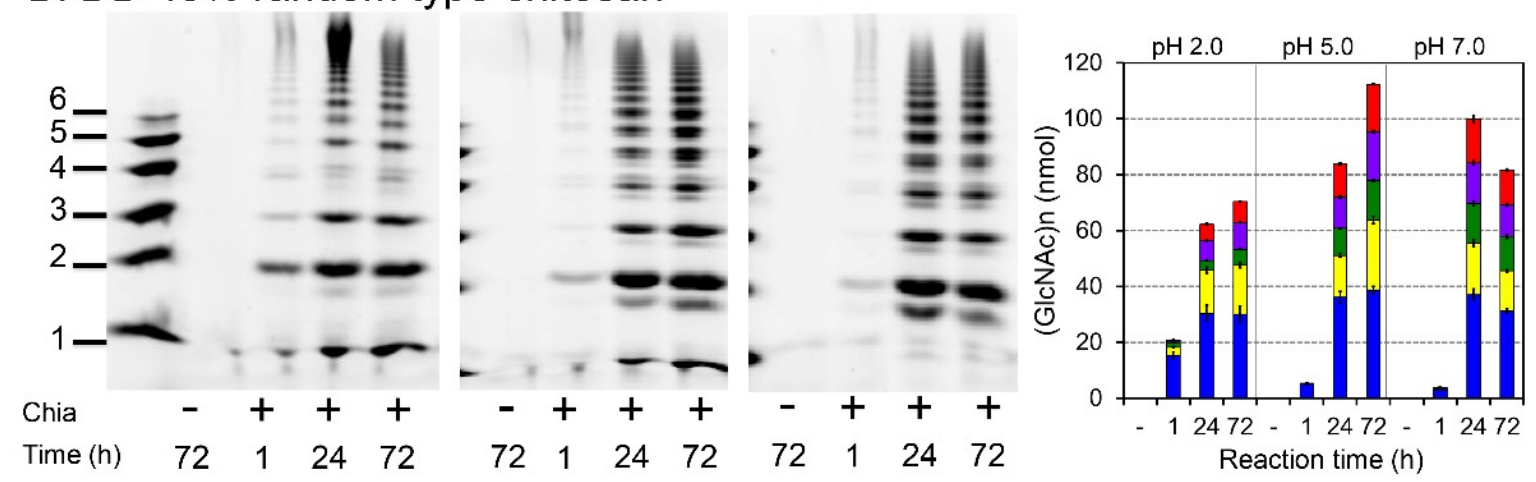

Figure 4. Degradation of random-type chitosan by Chia under different $\mathrm{pH}$ conditions. Chitosan was directly dissolved in water and incubated with Chia at $\mathrm{pH} 2.0,5.0$, or 7.0 and $37^{\circ} \mathrm{C}$ for 1,24 , or $72 \mathrm{~h}$, followed by the FACE method described in the Materials and Methods. Chitosan with DD 36\% (A) and DD 45\% (B) was used. Chitin oligomers are shown in the left margin as standards. Quantification of the data is shown in the right panels.

2.5. Chia Produces Chitooligosaccharides more Efficiently and with Higher Size Variability from Random-Type Chitosan

We compared the degradation products of block-type chitosan with $69 \%$ and randomtype chitosan with $45 \% \mathrm{DD}$. The substrates were dissolved directly in Mcllvaine buffer (pH 2.0), incubated with Chia at $37^{\circ} \mathrm{C}$ for 1,24 , or $72 \mathrm{~h}$ and analyzed by the FACE method. The pattern and efficiency of the degradation differed significantly between the two types of chitosan substrates (Figure 5, upper). Furthermore, more chitooligosaccharides can be obtained by prolonged incubation with Chia ( 24 and $72 \mathrm{~h}$ ) than by the 1-h incubation (Figure 5, upper). Quantitative analysis indicated that higher levels of chitooligosaccharides with more variable lengths were produced from random-type chitosan rather than from the block-type form of the molecule (Figure 5, lower). In the random-type chitosan, the distribution of the chitooligosaccharides was more even, but the variability in terms of the oligomers' presence was very similar. These results suggest that the differences in the degradation efficiency and pattern can be affected by the presence of crystal structure and the DD mode of the substrates. It appears that the DD can change the substrate affinity to the enzyme. 

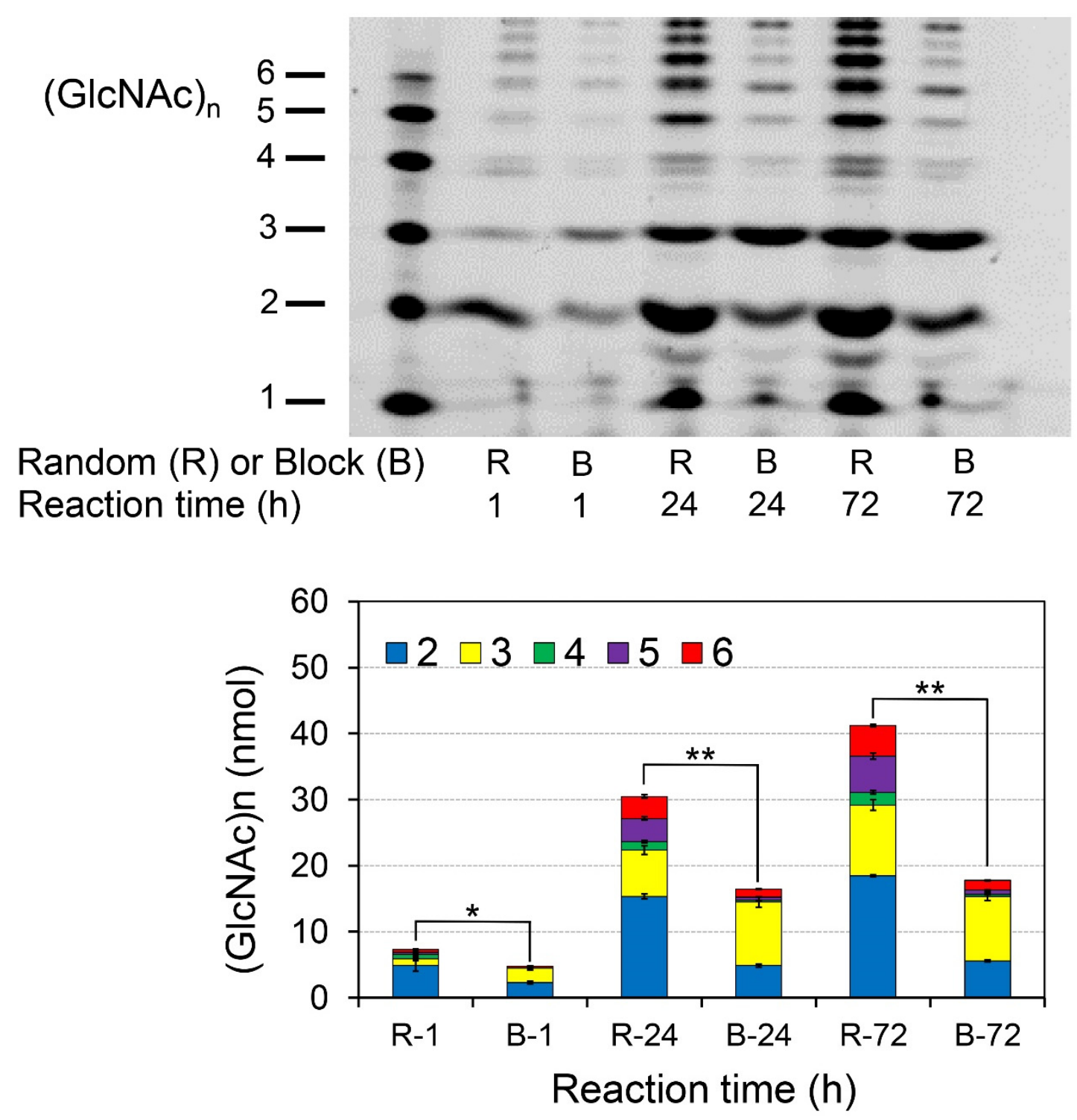

Figure 5. Chia produces chitooligosaccharides with more variable sizes from random-type chitosan when compared to the block-type form. Direct comparison of the degradation products from DD 69\% block-type (B) and DD 45\% random-type (R) chitosan substrates is essentially as described in Figures 3 and $4 .{ }^{*} p<0.05 ;{ }^{* *} p<0.01$.

\section{Discussion}

We have previously shown that mouse Chia degrades $\alpha$-chitin exclusively to $(\mathrm{GlcNAc})_{2}[28,30,31]$. Here we show that mouse Chia produces chitooligosaccharides from the block- and random-type chitosan substrates under $\mathrm{pH}$ conditions present in different mammalian tissues.

Chitosan and chitooligosaccharides have attracted substantial interest due to their biomedical activities that include anti-microbial [49], anti-inflammatory [50], and antitumor effects [51]. It remains, however, unclear whether chitooligosaccharides are spontaneously produced in vivo. We showed that Chia could degrade block-type chitosan substrates at $\mathrm{pH} 2.0$ and random-type chitosan at $\mathrm{pH}$ 2.0-7.0. The quantitative FACE analysis revealed that the degradation product pattern of chitooligosaccharides differs depending on the substrate and reaction conditions. The produced chitooligosaccharides may trigger several cascades, such as anti-pathogen and immune responses in the living organisms. These data can be applied to in vivo studies aiming to understand the physiological importance of the chitooligosaccharides. 
More efficient degradation with higher chitooligosaccharides' size variability was observed from the random-type chitosan as compared to the block-type chitosan. Our results suggest that structural differences between chitin and chitosan can regulate the substrate specificity of Chia and can significantly alter the composition of the resulting degradation products. The block-type chitosan has amorphous regions, which are highly deacetylated areas (GlcN-rich), so Chia targets a cluster of the acetylated areas and produces mainly dimers and trimers (Figure 6, left). In contrast, when targeting the random-type chitosan, Chia preferentially degrades the randomly placed GlcNAc-rich regions to produce more variable-sized chitooligosaccharides (Figure 6, right). Random-type chitosan with $\mathrm{DD}$ around $50 \%$ is water-soluble and more versatile than other chitosan substrates. Thus, we propose the random-type chitosan as a suitable substrate for producing chitooligosaccharides in terms of quantity and quality for agricultural, pharmaceutical, and medical purposes.

\section{Block-type chitosan (DD 69\%)}

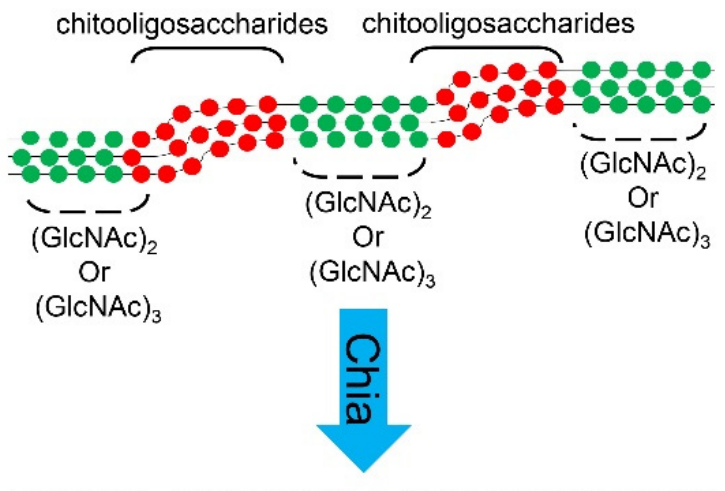

$(\mathrm{GlcNAc})_{2}$ or $(\mathrm{GlcNAc})_{3}>$ Chitooligosaccharides
Random-type chitosan (DD 45\%)

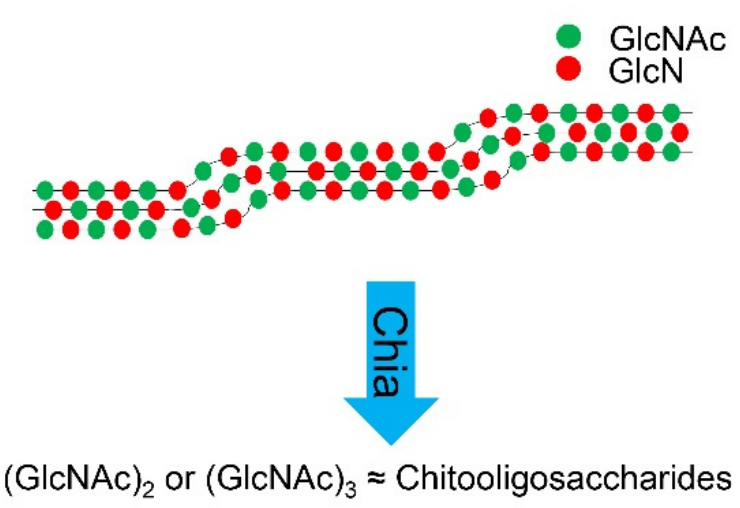

Figure 6. Chitosan structure and mode of degradation by Chia. The chitosan structure and mode of degradation by Chia are illustrated.

Interestingly, $\mathrm{DD}$ of the random-type chitosan affected the $\mathrm{pH}$-dependence of the degradation rate (Figure 4A,B). We have previously reported that mouse Chia shows higher transglycosylation and weaker glycosidase activity under neutral conditions than at acidic $\mathrm{pH}$ [32]. Importantly, substrate degradation and transglycosylation by Chia can occur simultaneously. Since Chia does not recognize the deacetylated (GlcN) regions, the enzyme degrades the GlcNAc areas formed through Chia's transglycosylation of the substrate. Thus, $45 \%$ DD chitosan was degraded more efficiently than the substrate with $35 \% \mathrm{DD}$. We speculate that the reaction mode and efficiency generally depends on the combination of $\mathrm{DD}$ and $\mathrm{pH}$.

The degradation products in this study were evaluated using the FACE method. This method is useful in analyzing sugars with various reducing ends, including chitooligosaccharides [30,52]. When compared with HPLC, which is often used to analyze chitooligosaccharides, there is a correlation between the two analytical methods in sugar identification and the degree of polymerization. Furthermore, FACE has several advantages: simple handling, high sensitivity, and low experimental costs [30]. However, this method is not able to analyze sugars that form the chitooligosaccharides [47]. To analyze the structure of individual degradation products, combination with NMR and MS analysis is necessary.

In agriculture, insect-based diets improve the growth performance and nutrient digestibility without affecting immune responses in poultries and pigs [53,54]. Furthermore, supplementation of chitooligosaccharides can enhance the immune response and function as an antibiotic/probiotic in pregnant pigs [54]. Recently, we have detected chitooligosaccharides after mealworm larvae or fly wing processing under chicken, pig, and marmoset 
gastrointestinal-like conditions $[34,35,37]$. The product patterns were similar to those obtained by chitosan digestion [34]. Our results showing Chia selectively degrading acetylated (chitin-like) areas of chitosan suggest that chitooligosaccharides can be produced in mammalian organisms from partially deacetylated chitin-containing organisms.

Since Chia expression is significantly altered under several pathological conditions such as asthma and allergic inflammation $[14,15]$, it has attracted substantial scientific attention. Recently, Chia was shown to be a constitutively produced enzyme essential for chitin degradation in bronchial airways to maintain lung functions [25,55]. Our present results indicate that Chia can degrade various types of chitosan under acidic to neutral conditions. They suggest that Chia can assist in the removal of invaded chitin-containing pathogens, such as mites and molds, while producing chitooligosaccharides that may have in addition local anti-inflammatory effects.

Recently, we reported that crab-eating monkey Chia has robust chitinolytic activity under broad $\mathrm{pH}$ and temperature ranges [56]. This enzyme is $2 \times, 16 \times$, and $10 \times$ more active at $\mathrm{pH}$ 2.0, 5.0, and 7.0, respectively, than mouse Chia. We suggest monkey Chia as a useful tool to act under various conditions to produce bioactive chitooligosaccharides efficiently. Further scrutiny on the chitosan degradation by monkey Chia is required to confirm its ability.

\section{Materials and Methods}

\subsection{Preparation of Recombinant Mouse Chia and Measurement of Chitinase Activity}

We expressed mouse Chia as a fusion protein of Protein A-Chia-V5-His in Escherichia coli, followed by its purification as described previously $[28,29,57]$. The chitinolytic activity was determined using 4-nitrophenyl $N, N^{\prime}$-diacetyl- $\beta$-D-chitobioside [4-NP-(GlcNAc) 2 , Sigma-Aldrich, St. Louis, MO, USA] as reported previously [28-30]. Chia unit definition has also been described previously [28].

\subsection{Preparation of $\alpha$ - or $\beta$-Colloidal Chitin}

Chitin samples were powdered in a Wiley mill (Thomas Scientific, Swedesboro, NJ, USA) to particles of approximately $250 \mu \mathrm{m}$. We prepared $\alpha$ - or $\beta$-colloidal chitin from shrimp shells (Sigma-Aldrich) or squid pen chitin (Katakura \& Co-op Agri Corporation, Tokyo, Japan) as described previously [28]. The suspended colloidal chitin was collected as a supernatant $(10 \mathrm{mg} / \mathrm{mL}) . \alpha$ - or $\beta$-Colloidal chitin $(2 \mathrm{mg} / \mathrm{mL})$ was incubated with Chia $(50 \mu \mathrm{U})$ in $50 \mu \mathrm{L}$ of Mcllvaine buffer ( $\mathrm{pH} 2.0)$ at $37^{\circ} \mathrm{C}$ for 1,24 , or $72 \mathrm{~h}$.

\subsection{Deacetylated Chitosan Substrates}

The block-type chitosan was a generous gift from Funakoshi Co., Ltd. (Tokyo, Japan) and was described previously [47]. The random-type chitosan substrates were prepared from $\alpha$-chitin, essentially described by Kurita et al. [8]. We determined the degree of deacetylation (DD) by elemental analysis as described previously (Table 1) [42].

\subsection{X-ray Diffraction}

Chitin and chitosan samples were powdered in the Wiley mill to a particle size of approximately $74 \mu \mathrm{m}$. The phase compositions of chitin and chitosan samples were recorded at room temperature by X-ray diffraction (XRD) patterns (Rigaku Miniflex 600, Tokyo, Japan) using $\mathrm{Cu}-\mathrm{K} \alpha$ radiation $(\lambda=1.5406)$, in the $2 \theta$ range from $5^{\circ}$ to $40^{\circ}$.

\subsection{Degradation of Block-Type Chitosan by Chia at $\mathrm{pH} 2.0$}

The block-type chitosan was dissolved in Mcllvaine buffer ( $\mathrm{pH} 2.0$ ) at $25^{\circ} \mathrm{C}$ for $24 \mathrm{~h}$ $(10 \mathrm{mg} / \mathrm{mL})$. The chitosan sample $(2 \mathrm{mg} / \mathrm{mL})$ was incubated with Chia $(50 \mu \mathrm{U})$ in a total volume of $50 \mu \mathrm{L}$ and incubated at $37^{\circ} \mathrm{C}$ for 1,24 , or $72 \mathrm{~h}$. 


\subsection{Degradation of Random-Type Chitosan by Chia under Physiological pH Conditions}

The random-type chitosan was dissolved in water at $25^{\circ} \mathrm{C}$ for $24 \mathrm{~h}(10 \mathrm{mg} / \mathrm{mL})$. The substrate solution $(2 \mathrm{mg} / \mathrm{mL})$ was incubated with Chia $(50 \mu \mathrm{U})$ in $50 \mu \mathrm{L}$ of Mcllvaine buffer ( $\mathrm{pH} 2.0,5.0$, or 7.0 ) at $37^{\circ} \mathrm{C}$ for 1,24 , or $72 \mathrm{~h}$.

\subsection{Analysis of Chitooligosaccharides by FACE}

The chitin and chitosan degradation products were analyzed by FACE as described initially by Jackson [54] and recently improved by our group [30,55,58]. This method can separate and detect very low amounts ( p pmol) of chitooligosaccharides according to their molecular weight, based on their differential migration rates through polyacrylamide gel $[30,54,55]$. The samples were quantified using the Luminescent Image Analyzer (ImageQuant LAS 4000, GE Healthcare, Piscataway, NJ, USA) as described previously [30,32,55].

\subsection{Statistical Analysis}

We used the Student's $t$-test for comparison between two sample groups. We considered the difference between comparisons to be significant when $p<0.05$ for the statistical analyses.

\section{Conclusions}

Our study showed that Chia could degrade various chitosan substrates under physiological conditions corresponding to different mammalian tissues, including stomach and

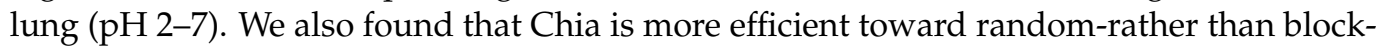
type chitosan, a water-soluble molecule with potential for a wide range of applications, including agriculture, food, and biomedicine fields.

Author Contributions: Conceptualization, S.W., Y.S., P.O.B. and F.O.; Methodology, S.W., Y.S. and F.O.; Validation, S.W., Y.S. and F.O.; Investigation, S.W., Y.S., M.N., S.K., K.M., C.T., M.K., Y.K., M.U., K.H. and S.S.; Formal analysis, S.W., Y.S., M.N., S.K., K.M., C.T., M.K., Y.K., M.U., K.H. and S.S.; Writing —review and editing, S.W., C.T., E.T., V.M., P.O.B. and F.O.; Project administration, F.O.; Funding acquisition, M.K., E.T. and F.O. All authors have read and agreed to the published version of the manuscript.

Funding: This work was funded by a grant from the Project Research Grant from the Research Institute of Science and Technology, Kogakuin University (to F.O.), Grants-in-Aid for Scientific Research (18J23382 (to M.K.) and 21J30001 (to E.T.)) from the Ministry of Education, Culture, Sports, Science, and Technology of Japan and the Science Research Promotion Fund of the Promotion and Mutual Aid Corporation (PMAC) for Private Schools of Japan (to F.O.).

Institutional Review Board Statement: All procedures in this study were reviewed and approved by the Recombinant DNA Committee at Kogakuin University.

Informed Consent Statement: Not applicable.

Data Availability Statement: Data supporting the reported results will be available with the corresponding author (Fumitaka Oyama).

Acknowledgments: We are grateful to Masayoshi Sakaguchi, Kazuaki Okawa, Shotaro Honda, Mitsuhiro Yuasa, Takashi Watanabe, Nao Kishigami, and Yasutada Imamura for their valuable suggestions.

Conflicts of Interest: The authors declare no conflict of interest.

Sample Availability: Samples of the compounds are available from the authors.

\section{References}

1. Wysokowski, M.; Petrenko, I.; Stelling, A.L.; Stawski, D.; Jesionowski, T.; Ehrlich, H. Poriferan chitin as a versatile template for extreme biomimetics. Polymers 2015, 7, 235-265. [CrossRef]

2. Calström, D. The crystal structure of $\alpha$-chitin (poly-N-acetyl-D-glucosamine). J. Biophys. Biochem. Cytol. 1957, 3, 669-683. [CrossRef]

3. Sikorski, P.; Hori, R.; Wada, M. Revisit of alpha-chitin crystal structure using high resolution X-ray diffraction data. Biomacromolecules 2009, 10, 1100-1105. [CrossRef]

4. Minke, R.; Blackwell, J. The structure of $\alpha$-chitin. J. Mol. Biol. 1978, 120, 167-181. [CrossRef] 
5. $\quad$ Rudall, K.; Kenchington, W. The chitin system. Biol. Rev. 1973, 49, 597-636.

6. Kaya, M.; Mujtaba, M.; Ehrlich, H.; Salaberria, A.M.; Baran, T.; Amemiya, C.T.; Galli, R.; Akyuz, L.; Sargin, I.; Labidi, J. On chemistry of $\gamma$-chitin. Carbohydr. Polym. 2017, 176, 177-186. [CrossRef]

7. Sannan, T.; Kurita, K.; Iwakura, Y. Studies on chitin, 2. Effect of deacetylation on solubility. Die Makromol. Chem. Macromol. Chem. Phys. 1976, 177, 3589-3600.

8. Kurita, K.; Sannan, T.; Iwakura, Y. Studies on chitin, 4. Evidence for formation of block and random copolymers of $N$-acetyl-Dglucosamine and D-glucosamine by hetero- and homogeneous hydrolyses. Macromol. Chem. Phys. 1977, 178, 3197-3202.

9. Bussink, A.P.; Speijer, D.; Aerts, J.M.; Boot, R.G. Evolution of mammalian chitinase(-like) members of family 18 glycosyl hydrolases. Genetics 2007, 177, 959-970. [PubMed]

10. Bueter, C.L.; Specht, C.A.; Levitz, S.M. Innate sensing of chitin and chitosan. PLoS Pathog. 2013, 9, e1003080. [CrossRef]

11. Lee, C.G.; Da Silva, C.A.; Dela Cruz, C.S.; Ahangari, F.; Ma, B.; Kang, M.J.; He, C.H.; Takyar, S.; Elias, J.A. Role of chitin and chitinase/chitinase-like proteins in inflammation, tissue remodeling, and injury. Annu. Rev. Physiol. 2011, 73, 479-501. [CrossRef]

12. Koch, B.E.; Stougaard, J.; Spaink, H.P. Keeping track of the growing number of biological functions of chitin and its interaction partners in biomedical research. Glycobiology 2015, 25, 469-482. [CrossRef]

13. Boot, R.G.; Blommaart, E.F.; Swart, E.; Ghauharali-van der Vlugt, K.; Bijl, N.; Moe, C.; Place, A.; Aerts, J.M. Identification of a novel acidic mammalian chitinase distinct from chitotriosidase. J. Biol. Chem. 2001, 276, 6770-6778. [CrossRef] [PubMed]

14. Zhu, Z.; Zheng, T.; Homer, R.J.; Kim, Y.K.; Chen, N.Y.; Cohn, L.; Hamid, Q.; Elias, J.A. Acidic mammalian chitinase in asthmatic Th2 inflammation and IL-13 pathway activation. Science 2004, 304, 1678-1682. [CrossRef] [PubMed]

15. Reese, T.A.; Liang, H.E.; Tager, A.M.; Luster, A.D.; Van Rooijen, N.; Voehringer, D.; Locksley, R.M. Chitin induces accumulation in tissue of innate immune cells associated with allergy. Nature 2007, 447, 92-96.

16. Bucolo, C.; Musumeci, M.; Maltese, A.; Drago, F.; Musumeci, S. Effect of chitinase inhibitors on endotoxin-induced uveitis (EIU) in rabbits. Pharmacol. Res. 2008, 57, 247-252. [CrossRef]

17. Musumeci, M.; Aragona, P.; Bellin, M.; Maugeri, F.; Rania, L.; Bucolo, C.; Musumeci, S. Acidic mammalian chitinase in dry eye conditions. Cornea 2009, 28, 667-672. [CrossRef]

18. Bucolo, C.; Musumeci, M.; Musumeci, S.; Drago, F. Acidic mammalian chitinase and the eye: Implications for ocular inflammatory diseases. Front. Pharmacol. 2011, 2, 43. [CrossRef] [PubMed]

19. Cozzarini, E.; Bellin, M.; Norberto, L.; Polese, L.; Musumeci, S.; Lanfranchi, G.; Paoletti, M.G. CHIT1 and AMCase expression in human gastric mucosa: Correlation with inflammation and Helicobacter pylori infection. Eur. J. Gastroenterol. Hepatol. 2009, 21, 1119-1126.

20. Nookaew, I.; Thorell, K.; Worah, K.; Wang, S.; Hibberd, M.L.; Sjovall, H.; Pettersson, S.; Nielsen, J.; Lundin, S.B. Transcriptome signatures in Helicobacter pylori-infected mucosa identifies acidic mammalian chitinase loss as a corpus atrophy marker. BMC Med. Genom. 2013, 6, 41. [CrossRef]

21. Bierbaum, S.; Nickel, R.; Koch, A.; Lau, S.; Deichmann, K.A.; Wahn, U.; Superti-Furga, A.; Heinzmann, A. Polymorphisms and haplotypes of acid mammalian chitinase are associated with bronchial asthma. Am. J. Respir. Crit. Care Med. 2005, 172, 1505-1509.

22. Seibold, M.A.; Reese, T.A.; Choudhry, S.; Salam, M.T.; Beckman, K.; Eng, C.; Atakilit, A.; Meade, K.; Lenoir, M.; Watson, H.G.; et al. Differential enzymatic activity of common haplotypic versions of the human acidic mammalian chitinase protein. J. Biol. Chem. 2009, 284, 19650-19658. [CrossRef]

23. Okawa, K.; Ohno, M.; Kashimura, A.; Kimura, M.; Kobayashi, Y.; Sakaguchi, M.; Sugahara, Y.; Kamaya, M.; Kino, Y.; Bauer, P.O.; et al. Loss and gain of human acidic mammalian chitinase activity by nonsynonymous SNPs. Mol. Biol. Evol. 2016, 33, 3183-3193. [CrossRef] [PubMed]

24. Fitz, L.J.; DeClercq, C.; Brooks, J.; Kuang, W.; Bates, B.; Demers, D.; Winkler, A.; Nocka, K.; Jiao, A.; Greco, R.M.; et al. Acidic mammalian chitinase is not a critical target for allergic airway disease. Am. J. Respir. Cell Mol. Biol. 2012, 46, 71-79. [CrossRef] [PubMed]

25. Van Dyken, S.J.; Liang, H.E.; Naikawadi, R.P.; Woodruff, P.G.; Wolters, P.J.; Erle, D.J.; Locksley, R.M. Spontaneous chitin accumulation in airways and age-related fibrotic lung disease. Cell 2017, 169, 497-509. [CrossRef] [PubMed]

26. Ohno, M.; Tsuda, K.; Sakaguchi, M.; Sugahara, Y.; Oyama, F. Chitinase mRNA levels by quantitative PCR using the single standard DNA: Acidic mammalian chitinase is a major transcript in the mouse stomach. PLoS ONE 2012, 7, e50381.

27. Ohno, M.; Togashi, Y.; Tsuda, K.; Okawa, K.; Kamaya, M.; Sakaguchi, M.; Sugahara, Y.; Oyama, F. Quantification of chitinase mRNA levels in human and mouse tissues by real-time PCR: Species-specific expression of acidic mammalian chitinase in stomach tissues. PLoS ONE 2013, 8, e67399. [CrossRef]

28. Kashimura, A.; Okawa, K.; Ishikawa, K.; Kida, Y.; Iwabuchi, K.; Matsushima, Y.; Sakaguchi, M.; Sugahara, Y.; Oyama, F. Protein A-mouse acidic mammalian chitinase-V5-His expressed in periplasmic space of Escherichia coli possesses chitinase functions comparable to CHO-expressed protein. PLOS ONE 2013, 8, e78669. [CrossRef]

29. Kashimura, A.; Kimura, M.; Okawa, K.; Suzuki, H.; Ukita, A.; Wakita, S.; Okazaki, K.; Ohno, M.; Bauer, P.O.; Sakaguchi, M.; et al. Functional properties of the catalytic domain of mouse acidic mammalian chitinase expressed in Escherichia coli. Int. J. Mol. Sci. 2015, 16, 4028-4042. [CrossRef]

30. Wakita, S.; Kimura, M.; Kato, N.; Kashimura, A.; Kobayashi, S.; Kanayama, N.; Ohno, M.; Honda, S.; Sakaguchi, M.; Sugahara, Y.; et al. Improved fluorescent labeling of chitin oligomers: Chitinolytic properties of acidic mammalian chitinase under somatic tissue pH conditions. Carbohydr. Polym. 2017, 164, 145-153. [CrossRef] 
31. Kimura, M.; Umeyama, T.; Wakita, S.; Okawa, K.; Sakaguchi, M.; Matoska, V.; Bauer, P.O.; Oyama, F. Direct comparison of chitinolytic properties and determination of combinatory effects of mouse chitotriosidase and acidic mammalian chitinase. Int. J. Biol. Macromol. 2019, 134, 882-890. [CrossRef]

32. Wakita, S.; Kobayashi, S.; Kimura, M.; Kashimura, A.; Honda, S.; Sakaguchi, M.; Sugahara, Y.; Kamaya, M.; Matoska, V.; Bauer, P.O.; et al. Mouse acidic mammalian chitinase exhibits transglycosylation activity at somatic tissue pH. FEBS Lett. 2017, 591, 3310-3318. [CrossRef] [PubMed]

33. Ohno, M.; Kimura, M.; Miyazaki, H.; Okawa, K.; Onuki, R.; Nemoto, C.; Tabata, E.; Wakita, S.; Kashimura, A.; Sakaguchi, M.; et al. Acidic mammalian chitinase is a proteases-resistant glycosidase in mouse digestive system. Sci. Rep. 2016, 6, 37756. [CrossRef]

34. Tabata, E.; Kashimura, A.; Wakita, S.; Ohno, M.; Sakaguchi, M.; Sugahara, Y.; Kino, Y.; Matoska, V.; Bauer, P.O.; Oyama, F. Gastric and intestinal proteases resistance of chicken acidic chitinase nominates chitin-containing organisms for alternative whole edible diets for poultry. Sci. Rep. 2017, 7, 6662. [CrossRef]

35. Tabata, E.; Kashimura, A.; Wakita, S.; Ohno, M.; Sakaguchi, M.; Sugahara, Y.; Imamura, Y.; Seki, S.; Ueda, H.; Matoska, V.; et al. Protease resistance of porcine acidic mammalian chitinase under gastrointestinal conditions implies that chitin-containing organisms can be sustainable dietary resources. Sci. Rep. 2017, 7, 12963. [PubMed]

36. Tabata, E.; Kashimura, A.; Kikuchi, A.; Masuda, H.; Miyahara, R.; Hiruma, Y.; Wakita, S.; Ohno, M.; Sakaguchi, M.; Sugahara, Y.; et al. Chitin digestibility is dependent on feeding behaviors, which determine acidic chitinase mRNA levels in mammalian and poultry stomachs. Sci. Rep. 2018, 8, 1461. [CrossRef] [PubMed]

37. Tabata, E.; Kashimura, A.; Uehara, M.; Wakita, S.; Sakaguchi, M.; Sugahara, Y.; Yurimoto, T.; Sasaki, E.; Matoska, V.; Bauer, P.O.; et al. High expression of acidic chitinase and chitin digestibility in the stomach of common marmoset (Callithrix jacchus), an insectivorous nonhuman primate. Sci. Rep. 2019, 9, 159. [CrossRef]

38. Aam, B.B.; Heggset, E.B.; Norberg, A.L.; Sorlie, M.; Varum, K.M.; Eijsink, V.G. Production of chitooligosaccharides and their potential applications in medicine. Mar. Drugs 2010, 8, 1482-1517. [CrossRef]

39. Khoushab, F.; Yamabhai, M. Chitin research revisited. Mar. Drugs 2010, 8, 1988-2012. [PubMed]

40. Masuda, S.; Azuma, K.; Kurozumi, S.; Kiyose, M.; Osaki, T.; Tsuka, T.; Itoh, N.; Imagawa, T.; Minami, S.; Sato, K.; et al. Anti-tumor properties of orally administered glucosamine and $\mathrm{N}$-acetyl-D-glucosamine oligomers in a mouse model. Carbohydr. Polym. 2014, 111, 783-787. [PubMed]

41. Azuma, K.; Osaki, T.; Minami, S.; Okamoto, Y. Anticancer and anti-inflammatory properties of chitin and chitosan oligosaccharides. J. Funct. Biomater. 2015, 6, 33-49. [CrossRef]

42. Kazami, N.; Sakaguchi, M.; Mizutani, D.; Masuda, T.; Wakita, S.; Oyama, F.; Kawakita, M.; Sugahara, Y. A simple procedure for preparing chitin oligomers through acetone precipitation after hydrolysis in concentrated hydrochloric acid. Carbohydr. Polym. 2015, 132, 304-310. [CrossRef] [PubMed]

43. Cabrera, J.C.; Cutsem, P.V. Preparation of chitooligosaccharides with degree of polymerization higher than 6 by acid or enzymatic degradation of chitosan. Biochem. Eng. J. 2005, 25, 165-172. [CrossRef]

44. Vishu Kumar, A.B.; Varadaraj, M.C.; Gowda, L.R.; Tharanathan, R.N. Low molecular weight chitosans-preparation with the aid of pronase, characterization and their bactericidal activity towards Bacillus cereus and Escherichia coli. Biochim. Biophys. Acta 2007, 1770, 495-505. [CrossRef]

45. Kumar, B.A.; Tharanathan, R.N. A comparative study on depolymerization of chitosan by proteolytic enzymes. Carbohydr. Polym. 2004, 58, 275-283.

46. Roncal, T.; Oviedo, A.; Lopez de Armentia, I.; Fernandez, L.; Villaran, M.C. High yield production of monomer-free chitosan oligosaccharides by pepsin catalyzed hydrolysis of a high deacetylation degree chitosan. Carbohydr. Res. 2007, 342, $2750-2756$. [CrossRef] [PubMed]

47. Tabata, E.; Wakita, S.; Kashimura, A.; Sugahara, Y.; Matoska, V.; Bauer, P.O.; Oyama, F. Residues of acidic chitinase cause chitinolytic activity degrading chitosan in porcine pepsin preparations. Sci. Rep. 2019, 9, 15609. [CrossRef]

48. Pacheco, N.; Garnica-Gonzalez, M.; Gimeno, M.; Barzana, E.; Trombotto, S.; David, L.; Shirai, K. Structural characterization of chitin and chitosan obtained by biological and chemical methods. Biomacromolecules 2011, 12, 3285-3290. [CrossRef] [PubMed]

49. Chien, R.C.; Yen, M.T.; Mau, J.L. Antimicrobial and antitumor activities of chitosan from shiitake stipes, compared to commercial chitosan from crab shells. Carbohydr. Polym. 2016, 138, 259-264. [CrossRef]

50. Qiao, Y.; Bai, X.F.; Du, Y.G. Chitosan oligosaccharides protect mice from LPS challenge by attenuation of inflammation and oxidative stress. Int. Immunopharmacol. 2011, 11, 121-127. [CrossRef]

51. Shen, K.T.; Chen, M.H.; Chan, H.Y.; Jeng, J.H.; Wang, Y.J. Inhibitory effects of chitooligosaccharides on tumor growth and metastasis. Food Chem. Toxicol. 2009, 47, 1864-1871. [CrossRef]

52. Jackson, P. The use of polyacrylamide-gel electrophoresis for the high-resolution separation of reducing saccharides labelled with the fluorophore 8-aminonaphthalene-1,3,6-trisulphonic acid. Detection of picomolar quantities by an imaging system based on a cooled charge-coupled device. Biochem. J. 1990, 270, 705-713.

53. Islam, M.M.; Yang, C.J. Efficacy of mealworm and super mealworm larvae probiotics as an alternative to antibiotics challenged orally with Salmonella and E. coli infection in broiler chicks. Poult. Sci. 2017, 96, 27-34. [CrossRef] [PubMed]

54. Jin, X.H.; Heo, P.S.; Hong, J.S.; Kim, N.J.; Kim, Y.Y. Supplementation of Dried Mealworm (Tenebrio molitor larva) on Growth Performance, Nutrient Digestibility and Blood Profiles in Weaning Pigs. Asian-Australas. J. Anim. Sci. 2016, 29, 979-986. [CrossRef] [PubMed] 
55. Van Dyken, S.J.; Locksley, R.M. Chitins and chitinase activity in airway diseases. J. Allergy Clin. Immunol. 2018, 142, 364-369. [CrossRef]

56. Uehara, M.; Tabata, E.; Okuda, M.; Maruyama, Y.; Matoska, V.; Bauer, P.O.; Oyama, F. Robust chitinolytic activity of crab-eating monkey (Macaca fascicularis) acidic chitinase under a broad $\mathrm{pH}$ and temperature range. Sci. Rep. 2021, 11, 15470. [CrossRef]

57. Kimura, M.; Wakita, S.; Ishikawa, K.; Sekine, K.; Yoshikawa, S.; Sato, A.; Okawa, K.; Kashimura, A.; Sakaguchi, M.; Sugahara, Y.; et al. Functional properties of mouse chitotriosidase expressed in the periplasmic space of Escherichia coli. PLoS ONE 2016, 11, e0164367. [CrossRef]

58. Kimura, M.; Umeyama, T.; Wakita, S.; Okawa, K.; Sakaguchi, M.; Matoska, V.; Bauer, P.O.; Oyama, F. Quantification of chitooligosaccharides by FACE method: Determination of combinatory effects of mouse chitinases. MethodsX 2020, 7, 100881. [CrossRef] [PubMed] 